\title{
COMPARING DATA ACQUISITION METHODOLOGIES FOR DTM PRODUCTION
}

\author{
Coppa U. ${ }^{\mathrm{a}}$, Guarnieri A. ${ }^{\mathrm{b}}$, Pirotti F. ${ }^{\mathrm{b}}$, Tarolli P. ${ }^{\mathrm{c}}$, Vettore A. $^{\mathrm{b}}$ \\ ${ }^{a}$ INGV Napoli, Italy \\ E-mail: coppa@ov.ingv.it \\ ${ }^{\mathrm{b}}$ CIRGEO - Inderdepartmental Research Center in Geomatics, University of Padova, via dell'Università 16, 35020 \\ Padova, Italy \\ ${ }^{\mathrm{c}}$ TESAF Department, University of Padova, via dell’Università 16, 35020 Padova, Italy \\ E-mail: alberto.guarnieri(francesco.pirotti,antonio.vettore, paolo.tarolli)@unipd.it
}

KEY WORDS: LiDAR, 3D Modelling, DTM, DSM, risk analysis

\begin{abstract}
:
In this paper we present the results related to several field campaigns conducted in the last three years in a small (4.4 $\mathrm{km} 2)$ wilderness basin in Carnia, a tectonically active alpine region in northeast Italy. The study area is a typical alpine debris-flow dominated catchment where several landslides, including a significantly large one, were observed and mapped. The field survey carried out in 2007, 2008, 2009 and 2010 were focused on the large landslide of the basins and they consisted in the following steps: 1 - development of an accurate GPS network, 2 - make use of a long range Terrestrial Laser Scanner (TLS) for a detailed and local analysis of landslide movements, 3 - merge the data with an airborne LiDAR for a large scale analysis of the processes.

Preliminary analysis consist in the comparison of different high resolution Digital Terrain Models (DTMs) in order to estimate the debris volume that has been triggered during the last movements of the landslides. Achieved results show that the integration between ALS and TSL data allows to produce DTMs of limited extent, with higher quality and level of detail. Such DTMs improve the capabilities for landslides analysis and modelling with respect to the use of LiDAR data only, even in areas providing limited or difficult access for the survey activity.
\end{abstract}

\section{INTRODUCTION}

Areas with significant sources of loose soil and rocks sediment sources are of particular importance for slope surface stability affecting mainly the loose soil cover colluvium, such events are particularly dangerous as liable to evolve into debris flows channelled by the engravings of lower order channels, affecting roads and houses. The triggering factor is generally attributable to an extreme meteorological event that is to infiltrate in the upper layers of the soil, not disposed of as quickly in the deeper parts and less permeable or through the bedrock. The unstable material is subsequently transferred, at least in part, in the channel network and increases solid transport, influencing the temporal dynamics of the propagation of the sediment along the drainage network and also the morphology of the riverbed. The ability to identify the greater or lesser susceptibility of the slope of a river basin is thus seen to be important both to a policy of risk prevention and for a correct evaluation of the budget of the sediments at the basin scale.

\section{STUDY AREA}

The study site considered in this work concerns the basin Miozza located in the municipality of Ovaro, $20 \mathrm{~km}$ north-west of Tolmezzo (Udine Province), in the Carnia Alpine Region on the border with Austria and Slovenia. The basin covers an area of ??approximately $10.7 \mathrm{~km} 2$ along which the elevation ranges from 470 me $2075 \mathrm{~m}$ above sea level, with an average of 1244 $\mathrm{m}$ above sea level The slope has an average value of about $33^{\circ}$ with a maximum of $77^{\circ}$ found in the area of the head of the basin (figure 1). This is an area without buildings; human presence is limited to the cattle grazing activity. The region has a climate typical of the Alps North East with short periods of drought detected mostly during the winter and summer and an average annual precipitation of more than $2000 \mathrm{~mm}$. This is one of the most rainy areas of Italy. Runoff during the months of May and June is dominated by the processes of melting snow. During the most intense weather events events such as floods, debris flows and channel slope instability processes are common. The vegetation covers $94 \%$ of the study area and consists of forest of tall trees (74\%), shrubs (10\%), and highaltitude pasture $(10 \%)$ and the remaining $6 \%$ is represented by rock formations, debris and loose soil.

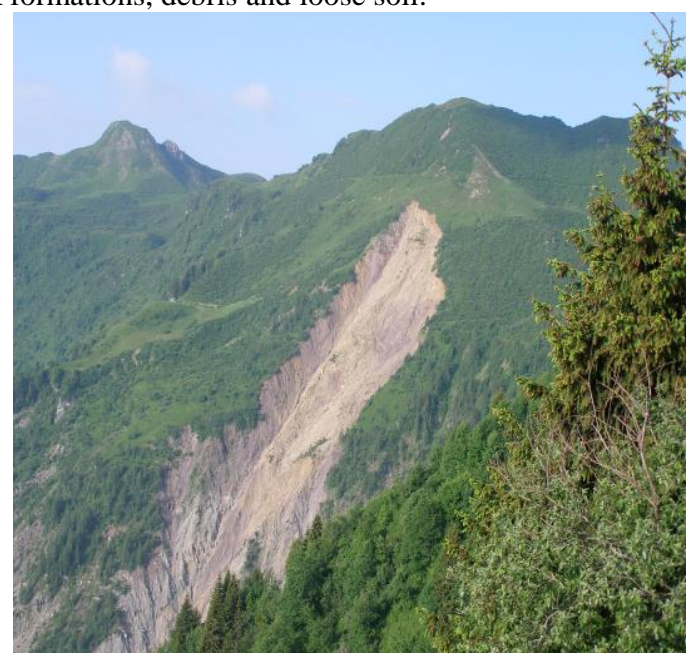

Figure 1 . The body of the landslide. 
This basin was chosen because it represents well a number of areas subject to the processes of surface disruption, as well as having also a geographic information system containing updated data on land use, morphology, topography of the site and an information database concerning the events of recent years. In addition there have been developed, in recent years many applications of hydraulic modeling (Tarolli and Tarboton, 2006; Tarolli and Dalla Fontana, 2008). Most of the areas of instability are localized in the channel head, in particular the bigger one alone covers an extension of 22 hectares (see figure 1) which is the most active and the main source of ignition of debris-flows that propagate along the main shaft almost to the closing section of the basin.

The landslide is of considerable size, and it cuts out the top of the South-West part of the basin. The main event occurred around the months of March / April 2005, and it has mobilized a considerable amount of stone material of silt-clay matrix as a result of water from the seasonal melting of snows. The soil covered the bed of the river for several hundred meters.

\section{MATERIAL AND METHODS}

In November 2003, before the reactivation of the main landslide body, the whole area was monitored using LiDAR equipment. The survey was performed in snow-free conditions using a ALTM 3033 OPTECH sensor and a digital camera, Rollei H20, mounted on helicopter. A flight altitude of $1000 \mathrm{~m}$ acquired an average point density of 2 points $/ \mathrm{m}^{2}$, recording both the first, intermediate and the last returns.

After this first survey, in 2004, there was significant movement of the landslide due to numerous events which triggered such dynamics. These changes brought to the necessity of planning a specific laser scanner survey using a Terrestrial Laser Scanner (TLS) along with a robust GPS network in order to allow having points of reference over time. In 2008 therefore a GPS network was created in stable points on the landslide, which has length of $650 \mathrm{~m}$ in its north-south axis and $130 \mathrm{~m}$ in its eastwest axis. Five vertices were measured and after that the area was surveyed with a Riegl ZM620.

\subsection{GPS Network}

The survey with GPS for establishing the network over the landslide area was performed with dual frequency GPS. The vertices were measured in static mode, with a stop-over time of 45 minutes in three separate sessions, thereby obtaining an overabundant number of observations sufficient to perform the compensation of the network. The instrumentation used were two receivers TOPCON HiPer Pro, a Leica System 200 and a Trimble 5700.

The five vertices of the network have been materialized by steel topographic nails properly cemented into the ground or inserted in the rock to allow successive and easy localization and to prevent possible movement due to the passing of local fauna or cattle. The average distance between the vertices of the network varies between $500 \mathrm{~m}$ and $1.5 \mathrm{~km}$.

The compensation network was done using the least squares estimation procedure, and it has provided a Standard Deviation value in the order of 2-3 mm, sufficient to monitor movements of the landslide over time.

The morphological complexity of the area has made it difficult to access the vertices of the network, whose position had been previously scheduled in the project planning of the relief.
Consequently, the GPS measurement campaign in the landslide was quite time consuming.

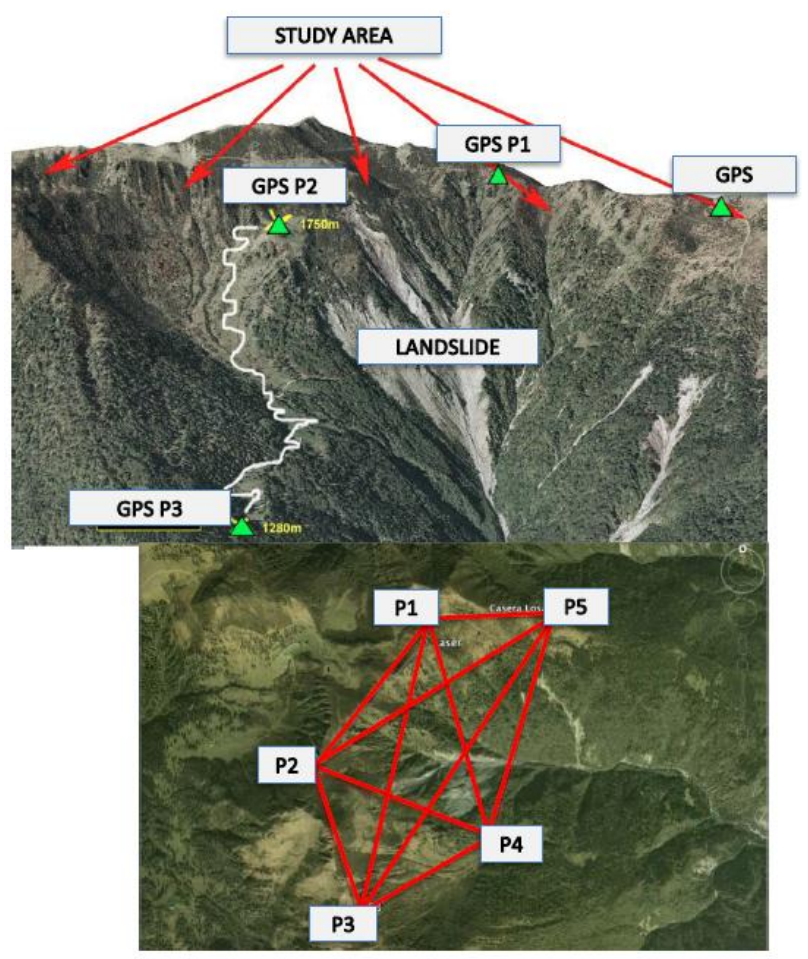

Figure 2. The five GPS points.

\section{RESULTS}

The three coordinates (N,E,h) of the five vertices used for monitoring $\mathrm{P}(1,2 \ldots 5)$ were considered to evaluate movement of the landslide. In the following two table the coordinate differences are reported, as well as the standard deviation of measures.

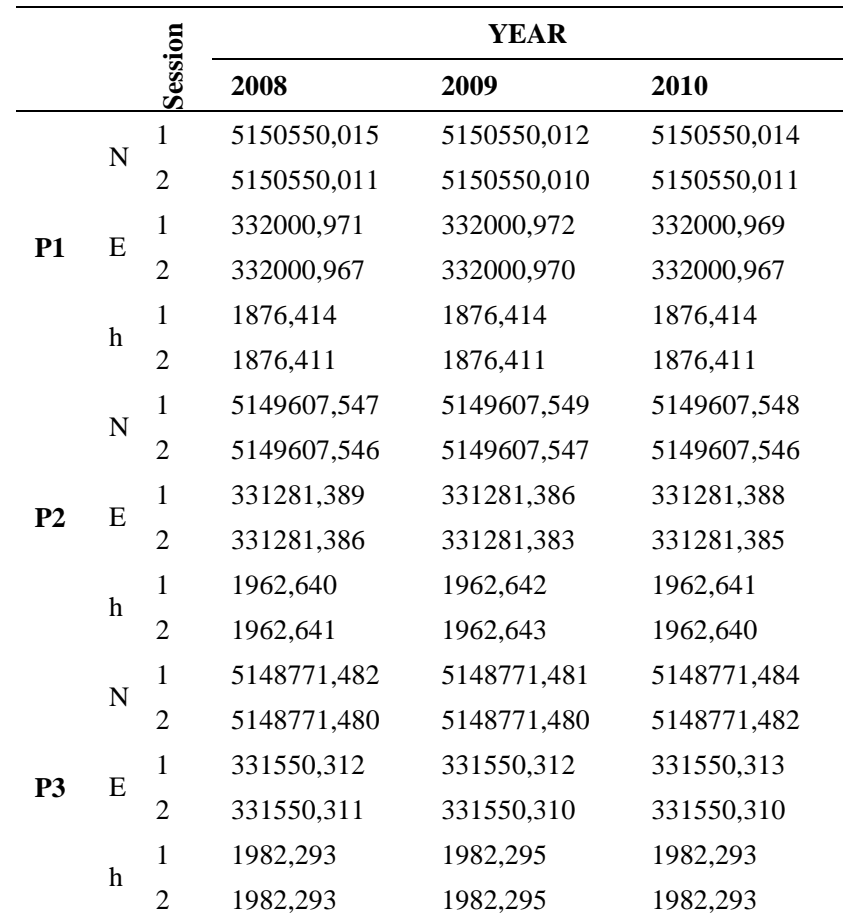




\begin{tabular}{|c|c|c|c|c|c|}
\hline \multirow{6}{*}{ P4 } & \multirow{2}{*}{$\mathrm{N}$} & 1 & 5149162,421 & 5149162,423 & 5149162,420 \\
\hline & & 2 & 5149162,420 & 5149162,420 & 5149162,420 \\
\hline & \multirow{2}{*}{ E } & 1 & 332377,049 & 332377,047 & 332377,048 \\
\hline & & 2 & 332377,047 & 332377,045 & 332377,046 \\
\hline & \multirow{2}{*}{$\mathrm{h}$} & 1 & 1466,066 & 1466,068 & 1466,064 \\
\hline & & 2 & 1466,064 & 1466,065 & 1466,060 \\
\hline \multirow{6}{*}{ P5 } & \multirow{2}{*}{$\mathrm{N}$} & 1 & 5150633,943 & 5150633,943 & 5150633,945 \\
\hline & & 2 & 5150633,940 & 5150633,941 & 5150633,945 \\
\hline & \multirow{2}{*}{ E } & 1 & 332827,745 & 332827,746 & 332827,744 \\
\hline & & 2 & 332827,741 & 332827,742 & 332827,742 \\
\hline & \multirow{2}{*}{ h } & 1 & 1654,324 & 1654,323 & 1654,322 \\
\hline & & 2 & 1654,321 & 1654,320 & 1654,320 \\
\hline
\end{tabular}

Table 1. GPS Coordinates over time and sessions.

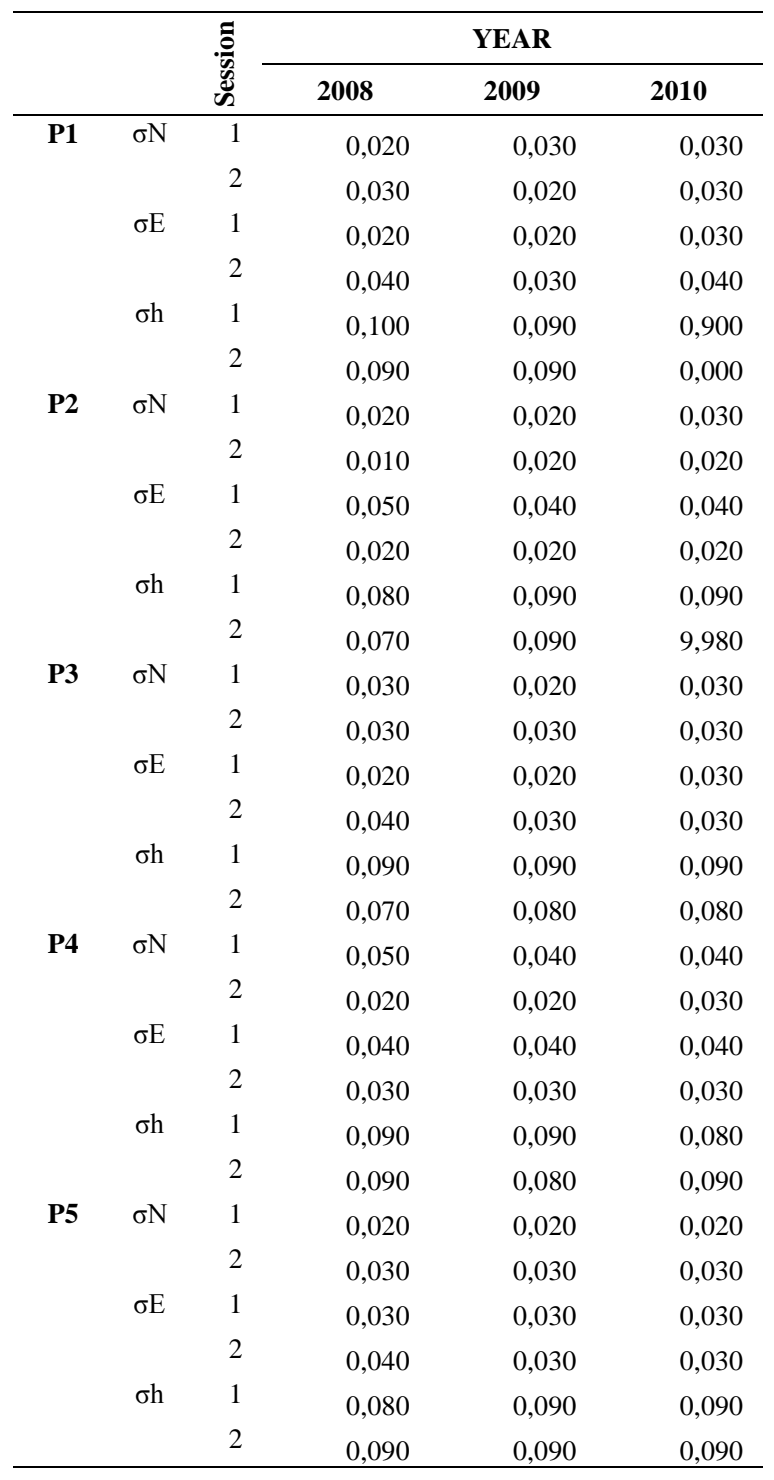

Table 2. Standard deviation of GPS measures.

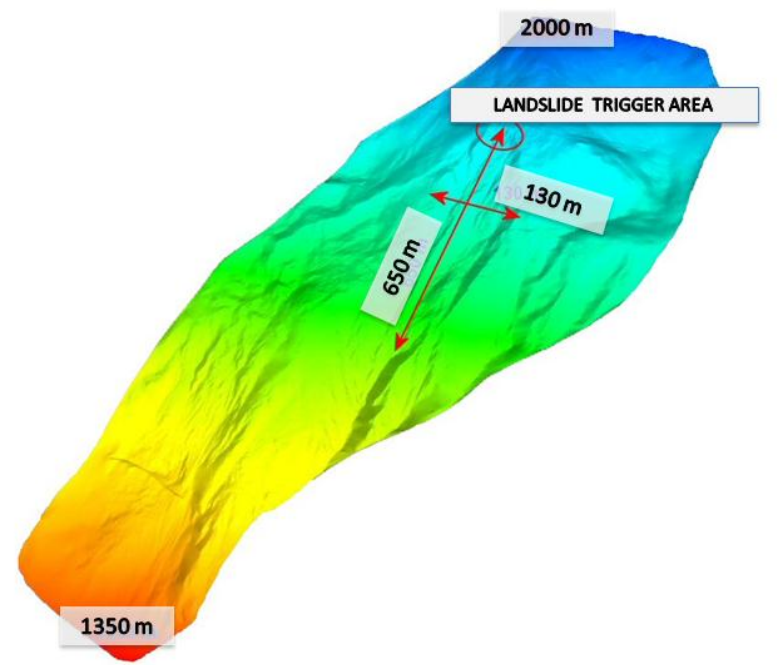

Figure 3. DTM model of the area with false colors

\subsection{Volumetric analysis}

The first processing step on the acquired data was the removal of vegetation present in the scans acquired with the terrestrial laser using a filtering procedure semi-automatically implemented in RiSCANPRO. Within this software, the resulting point cloud was then georeferenced using the LiDAR data from the 2003 survey. In order to improve the precision of the georeferencing step using the method of orientation of known point described above, the co-registration between TLS and LiDAR data has been improved by exploiting the automatic alignment procedure (Multi-Station-Adjustment) implemented in RiSCANPRO based on ICP (Iterative Closest Point). To do this, given the wide extension of the slope surveyed with the Riegl Z620 (figure 3), we used areas of overlap between the LiDAR point cloud and the TLS point cloud consisting of points external to the main body of the landslide. The result of this operation is shown in figure 4 , in which the point cloud acquired with TLS and textured images with your digital camera Nikon D200, appears correctly overlapping the LiDAR data. Subsequently, the DTM obtained from the measurements acquired with the two laser instruments (Riegl Z620 and Optech ALTM 3033) were compared with each other.

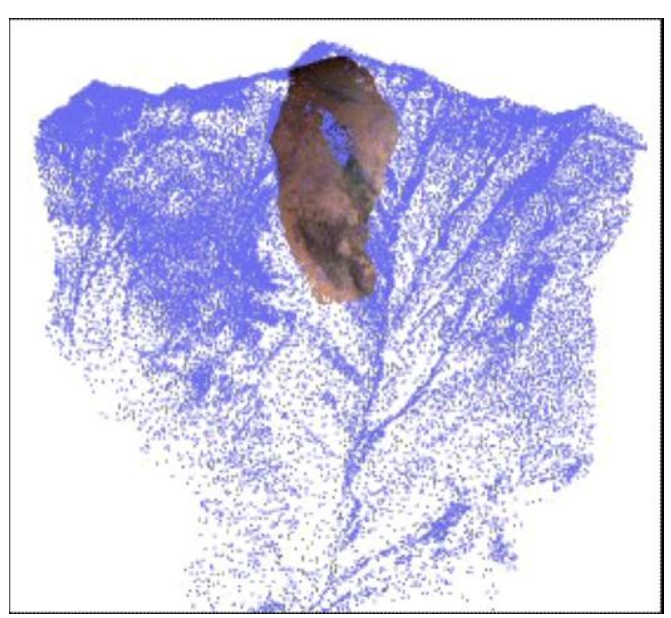

Figure 4 . The area analyzed for volume differences.

The comparison showed (see figure 5) a volumetric mobilization of massive material in the upper part of the 
landslide (about $221000 \mathrm{~m}^{3}$ ) and a partial deposition in the lower areas (around $63000 \mathrm{~m}^{3}$ ), as shown in Figure 5. The values obtained are in agreement with results as shown in previous studies conducted in the same area through the comparison between DEM derivatives, however, only measures from ALS (Barbarella et al., 2009; Massari et al., 2007) acquired also in this case before and after the event landslide.

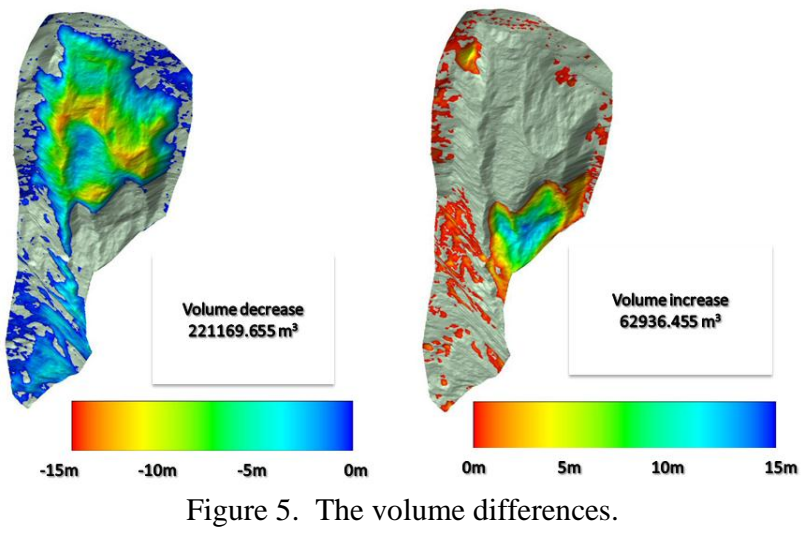

\section{CONCLUSIONS}

The results obtained from these applications show the high potential of the use of terrestrial laser scanning technology for the recovery of three-dimensional models useful for the monitoring of slopes subjected to hydro-geological instability. The work shows that through the integration of LiDAR surveys acquired from aircraft measurements and from terrestrial laser scanning it is possible to do the following analysis: i) to generate a high resolution DTM with higher quality and detail, also in areas with very low accessibility, improving the possibility for analysis and modelling of landslides that before could only be achieved with ALS measures, ii) to operate in areas which are not accessible or which have very complex morphology, collecting data even in those parts of the study site where the morphology creates areas void of points due to the scanning geometry.

The use of terrestrial laser scanning as a tool for the monitoring and the analysis of landslides affecting the basin Miozza does not end with the work presented here. We believe the it is necessary to improve in particular two issues: the comparison between the studies of mountain basins based on LiDAR data alone without TLS information and the quantification of landslides through multitemporal TLS surveys without LiDAR data.

\section{REFERENCES}

Barbarella, M., Fiani, M., Pistillo, P., 2009. Monitoraggio dell'evoluzione di una frana tramite Laser Scanning. In: National Conference ASITA, Bari Italy, 1-4 December 2009.

Massari, G., Paganini, P., Potleca, M., Torresin, M.T. 2007. Controllo dei dissesti su un bacino montano tramite analisi multitemporale, In: 10th Esri User Conference, Rome, Italy.

Pirotti, F., Guarnieri, A., Vettore, A., 2013. State of the art of ground and aerial laser scanning technologies for highresolution topography of the earth surface. European Journal of Remote Sensing 46, 66-78
Tarolli, P., Dalla Fontana, G., 2008. High resolution LiDARderived DTMs: some applications for the analysis of the headwater basins' morphology. International Archives of Photogrammetry, Remote Sensing and Spatial Information Sciences, 36(5/C55), pp. 297-306.

Tarolli, P., Tarboton, D.G., 2006. A New Method for Determination of Most Likely Landslide Initiation Points and the Evaluation of Digital Terrain Model Scale in Terrain Stability Mapping, Hydrol. Earth Syst. Sci., 10, 663-677.

Guarnieri A., Vettore A., 2006. Tecniche di registrazione. In: Sistemi a scansione per l'Architettura e il Territorio. Firenze, Alinea Editrice. 